\title{
Phonological Processes in Ekegusii Borrowing: A Constraint-based Approach
}

Edinah Gesare Mose

Department of Linguistics, Literature and Foreign Languages, Kenyatta University, Nairobi, Kenya

email: gesaremose@gmail.com

Received:

August 25,

2021

Revised:

November 01, 2021

Accepted:

November 03, 2021

\begin{abstract}
Phonological processes are at the heart of linguistic borrowing as it has varied phonological systems. It could be seen that the loan words entering the loan language from the source language can hardly be separated from the phonological process because they must be modified to suit the phonology of the loan language. This article analysed the phonological processes realized in Ekegusii borrowing from English using Optimality Theory's constraint approach. Since this was a phonological study, descriptive linguistic fieldwork was used. The data used in this article was extracted from Mose's doctoral study, whereby purposive sampling was used to obtain two hundred borrowed segments from the Ekegusii dictionary, then supplemented by introspection. Further, three adult native proficient Ekegusii speakers who were neither too young nor too old and had all their teeth were purposively sampled. The two hundred tokens were then subjected to the sampled speakers through interviews to realize the sound patterns in the Ekegusii borrowing process overtly. The findings revealed that Ekegusii phonological constraints defined the well-formedness of the loanwords by repairing the illicit structures. To fix, various phonological processes were realized. They included: epenthesis, deletion, devoicing/strengthening, voicing/ weakening, re-syllabification, substitution, monophthongization, and lenition. The article concludes that borrowing across languages (related or unrelated) reports similar if not the same phonological processes only that the processes attested in one language are a subset of the universally exhibited phonological processes.
\end{abstract}

Keywords: Constraints; Epenthesis; Optimality; Phonological Processes; Phonotactics.

\section{INTRODUCTION}

Loanword adaptation is primarily a phonological process; the donor words undergo phonological repairs to adapt to the recipient's segmental, phonotactic, and supra-segmental constraints (Tsvetkov \& Dyer, 2016). Further, loanword phonology reveals adaptations employed by native speakers who possess a phonological system to perceive and produce forms that belong to another phonological system (Sarkar, 2012). Because this process is entirely phonological, the loanwords entering a borrowing language from a source language undergo structure modification to conform to the borrowing language's phonological constraints. Since language phonologies are different, loanword adaptations are modified because foreign segments often contain alien structures that lack the underlying forms in the native phonology. Coincidentally, 
when languages borrow from each other, the structure modification of the loanwords may occur to individual segments or at the syllabic level. This ensures that strings that break the syllable structure or other phonotactics in the borrowing language are disallowed (Gussenhoven \& Jacobs, 2005). Hence, the phonological processes realized are either at the segmental or syllabic levels.

Ekegusii, a Bantu language spoken in Kenya, classified as E42 by Guthrie (1971), has a very different phonology from English, which is essentially a Germanic language of the Indo-European family. The two languages had had a historical contact which can be traced back to the colonial period when English was introduced by the British colonial government (Kioko \& Muthwii, 2001). Even today, English is used as the official language in that it used in the education sector, government, parliament, diplomacy and to conduct business internationally (Ogechi \& Kembo-Sure, 2006; the Kenyan Constitution, 2010). This contact situation has led to Ekegusii borrowing from English in an attempt to enrich its lexis; therefore, exhibiting various phonological processes that the article investigated.

Studies have been done on the phonological processes that occur during adaptation at the segmental and syllabic levels as a result of differences in the languages' phonology. One such study is by Iribemwangi and Karuru (2012) who study the borrowing of the Gĩ-Gĩchũgũ dialect of Gĩkũyũ language from Kiswahili. They establish that Gĩ-Gĩchũgũ in the adaptation of consonants employs deletion, preservation, substitution, and importation. Conversely, in the adaptation of vowels, the phonological processes reported include insertion, preservation, and substitution. These phonological processes ensure that the borrowed segments are as similar as possible to the source forms. GĩGĩchũgũ dialect of Gikuyu is a Bantu language just like Ekegusii. Therefore, there was the need to establish if Ekegusii reported similar phonological processes when borrowing from English. Saleh and Jarrah (2013) study English loanword phonology in Madin Hijazi Arabic (MHA). They establish that phonological changes observed include epenthesis, consonant voicing, vowel change, and re-syllabification to maintain the MHA phonological structures. Similarly, Zafaranlu and Hashemi (2011) report that insertion, prothesis, no palatalized consonants and no noun ending in the central low short vowel [a] are the phonological processes reported in Russian loanword adaptation in Persian. In addition, Faezeh and Zafaranlu (2013) observe that initial consonant clusters of German loanwords are broken through vowel epenthesis, which is mostly identical to the second syllable's vowel and reduction in reduction diphthongs as well as the substitution of phonemes. Madin Hijazi Arabic and Persian are very different from Ekegusii language; thus, it was necessary to establish whether Ekegusii phonological processes can be accounted for in reference to the languages mentioned.

Sarkar (2012) notes that loanwords undergo phonological changes at two levels: segmental level and syllabic level. At the segmental level, loaned consonants in the onset and coda positions undergo two processes; deletion and substitution. The phonological processes reported in Bangla are at the syllabic level, compensatory lengthening, consonant deletion, feature change, vowel epenthesis, cluster tolerance and germination. Equally, Ayuni (2012) notes that the most frequent phonological process is epenthesis, 
followed by sound strength and deletion change. Ayuni further observes that dissimilation and metathesis are infrequent processes in Indonesian borrowed words. Though Ayuni and Sarkar's studies are on Southern Asian languages, they report various phonological processes that are accounted for using the constraint based approach. These phonological processes needed to be ascertained in Ekegusii borrowing.

Fossi (2012) does an analysis of English loanwords in Ngəmbà, a Bantu language spoken in the West Region of Cameroon. The findings reveal that borrowed words undergo: cluster simplification, consonant-vowel reinterpretation, schwa deletion, voicing, devoicing, and tone insertion. These phonological processes reported in Ngəmbà necessitated this investigation to establish if they are the same since it is a Bantu language just like Ekegusii. Moreover, Fossi' findings on phonological processes are somewhat similar to those that Chacha (2009) reports in his analysis of loanwords from Arabic to Kiswahili which are: vowel epenthesis to repair syllables, feature change, consonant deletion and cluster tolerance. Chacha further adds that Kiswahili's open syllabicity (NOCODA) faithfulness constraint dominates the markedness of the sonority hierarchy (SON-SEQ) in the borrowed words. These phonological processes needed to be looked into in Ekegusii since Chacha points out that though Kiswahili is Bantu, it is prone to consonant clusters within syllables because of its long-time association with non-Bantu languages (English and Arabic), leading to the realization of cluster tolerance.

The studies reviewed indicate the extent to which languages adjust foreign segments in an effort to make them fit their language phonologies; therefore, realizing various phonological processes. By borrowing words from English, Ekegusii speakers are faced with sound combinations which are not present in the language's inventory. Thus, Ekegusii phonological constraints determine the structure modification of the loanwords which leads to the realization of various phonological processes which this article investigated. Further, although there exists extensive literature on language borrowing and especially on phonological processes attested across languages as already shown, little has been done specifically on Ekegusii phonological processes in borrowing. Therefore, this article adds knowledge to the continuing research on loanwords in African languages and in particular, on phonological processes.

\section{METHOD}

This article is an extraction of Mose's doctoral study (2020). In the main study, a descriptive linguistic fieldwork was used; since it painted a picture of the phenomenon of borrowed segments in Ekegusii and the subsequent phonological processes. Purposive sampling was carried out in two stages. First, it was used re-illicit two hundred words from the Ekegusii dictionary, which were then supplemented by introspection. Further, three adult proficient Ekegusii speakers (two males, one female) who were neither too young nor too old and had all their teeth were sampled. Bowern (2008) notes that the young or older speakers have less or no control over their articulators. The respondents were then interviewed to overtly realize the sound patterns in the Ekegusii borrowing process. Spoken data was sought because it was assumed that native speakers in their articulation have inherent native speaker competence which detects what is well and ill 
formed in the language. Hence, when faced with foreign elements like borrowed segments, they initiate structure modification leading to phonological processes. Besides, articulation revealed performance which was by extension adaptation. Moreover, spoken data elicited from the interviews using the wordlist, was recorded in sound proof language laboratory, transcribed then analysed using Optimality Theory's constraint approach (Prince \& Smolensky, 1993; 2004). The theory proposes that the grammar of all languages have a set of universal constraints which are part of Universal Grammar or the innate language knowledge that humans have. Since the constraints are universal, languages differ because they have varied phonologies. This variation in the phonologies of languages determines how the languages rank a set of universal constraints, resulting in an individual language's constraint hierarchy. Using these universal constraints, Ekegusii borrowed segments were analysed to determine optimal and their underlying phonological processes. A significant limitation to this investigation was the influence of education on the adaptations of borrowed words in Ekegusii since articulations were vital in identifying the phonological processes. This is because formal education enables speakers to acquire sounds that are not in their inventory, therefore affecting modification of loanwords. However, the researcher overcame this by employing adult native speaker competence in instances where the realizations of the sound patterns did not correspond to the Ekegusii phonotactics.

\section{FINDINGS AND DISCUSSION}

When the speakers of the Ekegusii language borrow words from English, they are faced with sound combinations not present in the language's inventory. Thus, Ekegusii phonological constraints defined the well-formedness of the output forms by repairing the illicit structures. In an effort to repair, various phonological processes were realized and are discussed herein with illustration from the data on loanwords.

\section{Epenthesis}

Epenthesis is the addition of one or more sound segments to a word (Sarkar, 2012). There are three types of epenthesis: excrescence, which is the addition of consonants; prothesis, addition of vowels at the initial point of a word usually with a phonotactic motivation while anaptyxis is the addition of vowel between two consonants. Epenthesis is also known as insertion. No instance of excrescence was observed in Ekegusii borrowing. Equally, Ekegusii did not witness any instance of prothesis. However, the insertion of ' $\mathrm{e}$ ' in word initial is a morphological rather than phonotactic realization whereby Ekegusii allows pre-prefixation. Anaptyxis was observed in the adaptation of the following loanwords:

\begin{tabular}{|c|c|c|}
\hline $\begin{array}{l}\text { English Input } \\
\text { /'fæktər1/ }\end{array}$ & $\begin{array}{l}\text { Ekegusii Output } \\
\text { [eßayitori] }\end{array}$ & $\begin{array}{l}\text { English Gloss } \\
\text { 'factory' }\end{array}$ \\
\hline /bre1k/ & [eßureki] & 'brake' \\
\hline /'bəolt/ & [eßoriti] & 'bolt' \\
\hline /'bælkən1/ & [eßarikoni] & 'balcony' \\
\hline /'b1sk1t/ & [eyesuyuti] & 'biscuit' \\
\hline
\end{tabular}




\begin{tabular}{|c|c|c|}
\hline /'helikpptə/ & [er1koßita] & 'helicopter' \\
\hline /'hed'ma:stə/ & [etumasita] & 'headmaster' \\
\hline /'hptppt/ & [eotißoti] & 'hotpot' \\
\hline /'k3:tn]/ & [ekateni] & 'curtain' \\
\hline /kən'd^ktə/ & [ekon dayita] & 'conductor' \\
\hline /'klınık/ & [ekiriniki] & 'clinic' \\
\hline /desk/ & [etesiki] & 'desk' \\
\hline /'fift1/ & 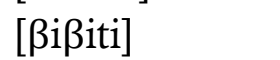 & 'fifty' \\
\hline /g la:s/ & [ekerasi] & 'glass' \\
\hline /'redz1stə/ & [erecesita] & 'register' \\
\hline /'lesn/ & [ereseni] & 'lesson' \\
\hline /ste1ds/ & [esiteci] & 'stage' \\
\hline /ste1fn/ & [esiteseni] & 'station' \\
\hline /slip/ & [esiri $\beta u]$ & 'slip' \\
\hline /sku:1/ & [esukuru] & 'school' \\
\hline /'sekrətr1/ & [esekeretari] & 'secretary' \\
\hline /'treslə/ & [eturera] & 'trailer' \\
\hline ['plæstık] & [eßurasitiki] & 'plastic' \\
\hline
\end{tabular}

Cluster consonants on syllable onset or coda are broken by inserting a vowel. There appears to be no predictable pattern governing the kind of vowel to be inserted to break the consonant clusters. However, what is clear are the constraints forbidding clusters at either position. This could be because complex onsets are cross-linguistically marked and therefore restricted in occurrence or wholly banned in some languages. Hence, epenthesis in an effort to break cluster consonants was reported in most of the reviewed studies. They included: Iribemwangi and Karuru (2012), Saleh and Jarrah (2013) Zafaranlu and Hashemi (2011), Faezeh and Zafaranlu (2013), Ayuni (2012) and Chacha (2009).

This cluster simplification can be accounted for using OT (Prince \& Smolensky, $1993 ; 2004)$. The theory proposes that the grammar of all languages has a set of universal constraints which are part of Universal Grammar or the innate language knowledge that humans have. However, the significance a language will attach to these various constraints differs. Thus, the phonology of a particular language is determined by how a language ranks a set of universal constraints, which results in a language's constraint hierarchy. First is the markedness constraint which presupposes that languages have 'marked' and 'unmarked' features. Whereas unmarked features are basic in all grammars and preferred cross-linguistically, marked are avoided cross-linguistically (Kager, 1999). In order to account for the Ekegusii's cluster simplification, which leads to epenthesis, the following markedness constraints as proposed by Nandelenga (2013); ${ }^{*} \mathrm{CO},{ }^{*} \mathrm{CN}$, ${ }^{*} \mathrm{CL}$ and ${ }^{*} \mathrm{CG}$ all of which are part of a family of constraints subsumed under the general anti-cluster constraint; ${ }^{*}$ COMPLEX ${ }_{\text {ONSET }}$ can be invoked. ${ }^{*} \mathrm{CG}$ in particular is low ranked because Ekegusii language allows it. In an input like /'redł1stə/ 'register' adapted as [e.re.ce.si.ta], there is a cluster of consonants and an obstruent repaired via vowel epenthesis. So, we can propose ${ }^{*} \mathrm{CO}_{\mathrm{ONS}}$ besides the undominated marked constraint 
*CODA. Equally, the schwa is not attested in the Ekegusii language; hence, *[REDUCED-V] is relevant. There is also devoicing of the post alveolar fricative, therefore, *[OBSVOI] can be invoked. Moreover, DEP-IO (V) constraint which forbids

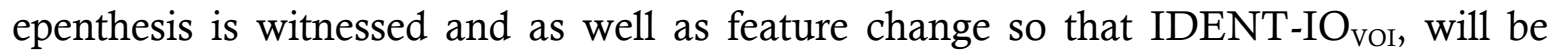
strictly dominated as follows:

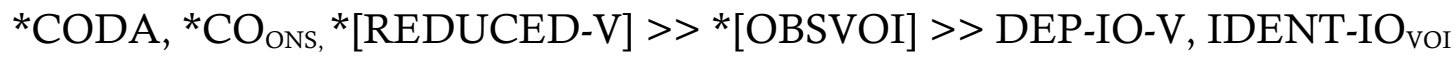

Table 1. Mapping of /'redz1stə/ $\longrightarrow$ [e.re.ce.si.ta] 'register'

\begin{tabular}{|c|c|c|c|c|c|c|}
\hline ['redz1stə] & ${ }^{*} \mathrm{CO}_{\mathrm{ONS}}$ & ${ }^{*} \mathrm{CODA}$ & $\begin{array}{l}{ }^{*}[\mathrm{REDU} \\
\mathrm{CED}-\mathrm{V}]\end{array}$ & *[OBSVOI] & $\begin{array}{l}\text { DEP- } \\
\text { IO-V }\end{array}$ & $\begin{array}{l}\text { IDENT- } \\
\mathrm{IO}_{\mathrm{VOI}}\end{array}$ \\
\hline a. [re.dz1.stə] & *! & & * & * & & \\
\hline b. $[$ e.re.ce.si.ta] & & & & & * & * \\
\hline c. [re.1dt.si.ta] & & $* !$ & & * & * & \\
\hline d. [e.re.ce.sta] & *! & & & & & * \\
\hline
\end{tabular}

The well-formed conditions prevail over the faithfulness conditions in Ekegusii. Consequently, though candidate (b) violates a faithfulness DEP-IO (V) constraint that demands structural similarity between input and output and IDENT-IO VoI, $_{\text {, which forbids }}$ feature change, it is the optimal form. Candidate (a) is the most disharmonic. It violates three marked constraints by allowing a complex onset, a schwa, and obstruent voicing that the Ekegusii language ranks highly. So, it does not survive.

On the other hand, candidate (c) does not fare well either. It incurs serious violations by violating the high ranked ${ }^{*}$ CODA and ${ }^{*}$ OBSVOI constraints which are ranked high in the language's hierarchy of constraints. Thus, it is eliminated. Candidate (d) is less harmonic compared with the optimal since it allows a complex onset. Hence, it is eliminated. Evidently, Ekegusii attaches more importance to cluster simplification and no coda than structural similarity between input and output. As a result vowel epenthesis is employed in both cases to ensure the loanword does not violate the language's phonology.

\section{Deletion}

Deletion is the omission of one or more sounds. Mostly, when deletion occurs, it may affect consonants, vowels, weak syllables or it may appear simply to break a consonant cluster. Deletion may take three forms. Aphaeresis, loss of a segment at the beginning of a word; syncope, the internal deletion of segments, that is, it occurs within a word and lastly, apocope, which is the loss of the final consonant.

Aphaeresis was observed in the mapping of the following loanwords to Ekegusii.

$\begin{array}{lll}\text { English Input } & \text { Ekegusii Output } & \begin{array}{l}\text { English Gloss } \\ \text { /'he.l1.kp.ptə/ }\end{array} \\ \text { [e.ri.ko.ßi.ta] } & \text { 'helicopter' }\end{array}$




$\begin{array}{lll}\text { /'hed.'ma:.stə/ } & \text { [e.tu.ma.si.ta] } & \text { 'headmaster' } \\ \text { /'hpt.ppt/ } & \text { [e.o.ti.ßo.ti] } & \text { 'hotpot' } \\ \text { /ha:f.t3:m/ } & \text { [e.a.ßu.ta.mu] } & \text { 'half term' }\end{array}$

The consonant $/ \mathrm{h} /$ is a voiceless glottal fricative. It functions in English essentially as a voiceless syllable-initial phoneme. In fact, some words have a silent $/ \mathrm{h} /$ in their spelling; however, because of its place of articulation (glottis) and being voiceless it is hardly audible. Besides, the Ekegusii inventory lacks it. Therefore, in the mapping it is easily deleted at word initial.

Further, syncope was evidenced in the following segments.

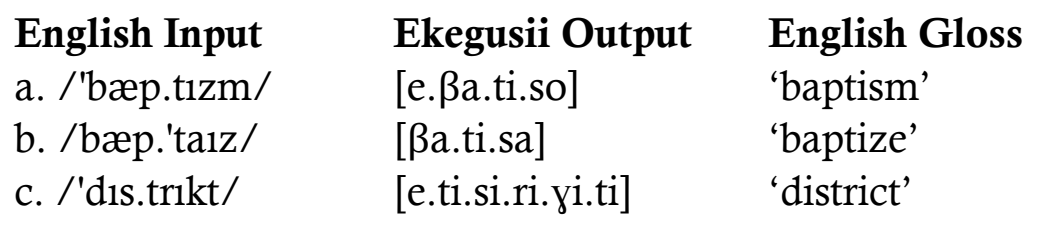

In segment (a), there is the deletion of $/ \mathrm{m} /$, in (b) $/ \mathrm{p} /$ is deleted while in (c), sound $/ \mathrm{t} /$ is deleted. In all the instances, the motivation is to break a consonant cluster. Clearly, Ekegusii language disallows cluster consonants hence, a constraint prohibiting their occurrence is ranked higher in the hierarchy and is undominated i.e. ${ }^{*} \mathrm{CN}$ just like *CODA which disallows coda consonants. Moreover, from the input output mapping of /'bæpt1zm/ as [e.ßa.ti.so] in Ekegusii, there is obstruent devoicing, thus the markedness constraints *OBSVOI is relevant as well as the deletion of the bilabial plosive $/ \mathrm{p} /$, hence * $[\mathrm{p}]$ constraint. Also, there is no correspondence between the input and output as deletion of consonants occurs as well as insertion of vowels. MAX-IO(C) as well as DEP-IO(V) are the consequent constraints and also IDENT-IO $\mathrm{VOI}_{\mathrm{VONNT}}$ which disallow feature change. They will be ranked as follows:

${ }^{*} \mathrm{CODA},{ }^{*} \mathrm{CN},{ }^{*}[\mathrm{p}]>>$ *OBSVOI $>>$ MAX-IO(C), DEP-IO(V), IDENT-IO vol/Cont

Table 2. Mapping of /'bæptızm/ $\longrightarrow \quad$ [e.ßa.ti.so] 'baptism'

The markedness constraints in this case dominate the faithfulness in Ekegusii. As

\begin{tabular}{|c|c|c|c|c|c|c|c|}
\hline /'bæptızm/ & ${ }^{*} \mathrm{CODA}$ & ${ }^{*} \mathrm{CN}$ & $*[p]$ & *OBSVOI & $\begin{array}{l}\text { MAX- } \\
\text { IO(C) }\end{array}$ & $\begin{array}{l}\text { DEP- } \\
\text { IO(V) }\end{array}$ & $\begin{array}{l}\text { IDENT- } \\
\text { IO }_{\text {VOI/CONT }}\end{array}$ \\
\hline a. [bæp.t1zm] & *! & * & * & * & & & \\
\hline b. $[$ e.ßa.t1.so] & & & & & ** & * & ** \\
\hline c. [e.ba.t1. 1s] & *! & & * & & ** & * & * \\
\hline d. [e.ßa.t1.zmo] & & *! & & * & * & * & * \\
\hline
\end{tabular}

a result, candidate (b) is the optimal form although it violates the faithfulness constrains which require some similarity between input and output. Nevertheless, (c) and (d) are eliminated. In fact, the two of them are isoharmonic, each of them violates two of the high ranked markedness constraints; ${ }^{*} \mathrm{CODA}$ and ${ }^{*}[\mathrm{p}]$ as well as ${ }^{*} \mathrm{CN}$ and ${ }^{*} \mathrm{OBSVOI}$ respectively which are ranked high in Ekegusii's hierarchy of constraints besides the 
faithfulness. As for candidate (a), it is the most disharmonic. It allows a coda worse still a complex coda, it has the voiceless bilabial plosive which is not attested in the language and allows the occurrence of a voiced obstruent; all these are constraints ranked very high in the language hierarchy. Evidently, Ekegusii's phonotactics pays more attention to structural markedness than similarity of input and output forms in borrowing phonemic segments.

No instance of apocope was observed in Ekegusii. Deletion either aphaeresis or syncope cross-linguistically was very prevalent in other Bantu languages like Gĩchũgũ (Iribemwangi \& Karũrũ, 2012), Bangla (Sakar, 2012) Ngəmbà, (Fossi, 2012) and Kiswahili (Mwita, 2009).

\section{Devoicing/ Strengthening and Voicing/ Weakening}

When a normally voiced consonant is pronounced without vocal-fold vibration in some context, it is said to be strengthened or devoiced (Gussenhoven \& Jacobs, 2005). Conversely, weakening or voicing occurs when a segment without vocal-fold vibration changes to be voiced in some contexts. Strengthening was observed in Ekegusii borrowing where the loanword had segments which are voiced, but when mapping occurred, they were devoiced.

\begin{tabular}{|c|c|c|}
\hline English Input & Ekegusii Output & English Gloss \\
\hline /'bæpt1zm/ & [eßatiso] & 'baptism' \\
\hline /'hed'ma:stə/ & [etumasita] & 'headmaster' \\
\hline /'kæbids/ & [ekaßici] & 'cabbage' \\
\hline /'d $\Lambda$ stə]/ & [etasita] & 'duster' \\
\hline /desk/ & [etesiki] & 'desk' \\
\hline /'ta:dzə/ & [ecaca] & 'charger' \\
\hline /'dzımpə/ & {$\left[\mathrm{eca}^{\mathrm{m}} \mathrm{ba}\right]$} & 'jumper' \\
\hline /dzu:s/ & [ecuisi] & 'juice' \\
\hline /'dzæk1t/ & [ecaketi] & 'jacket' \\
\hline /'trezərə/ & [eturesara] & 'treasurer' \\
\hline
\end{tabular}

Voiced obstruents are strengthened or devoiced when the loanwords are adapted in Ekegusii. For instance, /z/ is adapted as /s/, /d/ as /t/, /3/ is adapted as /s/ and $/ \mathrm{d} / \mathrm{as} / \mathrm{c} /$. In all the instances, the motivation was the absence of the voiced obstruents in the Ekegusii inventory besides the fact that voiceless sounds are unmarked, hence cross-linguistically preferred over the voiced sounds. Similarly, Ayuni (2012) and Fossi (2012) notes that sound strengthening or devoicing is very frequent in the Indonesian borrowed words and Ngəmbà, respectively.

Thus, this adaptation of voiced obstruents can be accounted for using OT. First, a constraint that prohibits obstruent voicing is imposed on the incoming loan. This is *[OBSVOI] in addition to the undominated *CODA constraint. Like for instance in the mapping of /'d $\Lambda$ stə/ as [etasita], there is the undominated *[REDUCED-V] which prohibits the occurrence of the reduced vowel. Ekegusii disallows cluster consonants as a result it is repaired through vowel epenthesis. In this case, $\mathrm{CO}_{\mathrm{ONS}}$ markedness 
constraint is proposed to evaluate the outputs further. Similarly, there is feature change whereby the inputs undergo devoicing. The faithfulness constraint IDENT-IO $\mathrm{VOI}_{\mathrm{vo}} \mathrm{can}$ be invoked. Furthermore, in most of the outputs there is vowel insertion so as to break consonant clusters. Therefore, DEP-IO(V) will be a relevant faithfulness constraint to account for the insertion. So, the constraints will be ranked as follows:

${ }^{*}$ CODA, ${ }^{*} \mathrm{CO}_{\text {ons, }}$ *[REDUCED] $>>$ *[OBSVOI] >> DEP-IO(V), IDENT-IO ${ }_{\text {voI. Table }}$ 3 presents the appropriate data to illustrate this obstruent devoicing.

\begin{tabular}{|c|c|c|c|c|c|c|}
\hline /'d $\mathrm{d}_{\mathrm{s} t \partial} /$ & ${ }^{*} \mathrm{CODA}$ & ${ }^{*} \mathrm{CO}_{\mathrm{ONS}}$ & $\begin{array}{l}{ }^{*}[\text { REDUC } \\
\text { ED-V] }\end{array}$ & *[OBSVOI] & $\begin{array}{l}\text { DEP- } \\
\text { IO-V }\end{array}$ & $\begin{array}{l}\text { IDENT- } \\
\text { IO }_{\mathrm{VOI}}\end{array}$ \\
\hline a. $[$ e.ta.si.ta] & & & & & * & * \\
\hline b. [d $\Lambda . s t \partial]$ & & $* !$ & * & * & & \\
\hline c. [e.da.si.at] & $\star !$ & & & * & * & \\
\hline d. [e.ta.stə] & & *! & * & & & * \\
\hline
\end{tabular}

Table 3 indicates that candidate (b) is the most disharmonic. It violates three of the high ranked markedness constraints which include: a complex cluster, realizes a voiced obstruent /d/ and has a schwa which is not attested in the language. Hence, it is thrown out. Candidate (a) incurs the less serious violations of the faithfulness constrains which demand structural similarity between input and output and are ranked low in the language. As a result, it is said to be optimal. However, (c) and (d) are isoharmonic, they each incur two of the more serious violations which are ${ }^{*} \mathrm{CODA},{ }^{*} \mathrm{OBSVOI}$ and ${ }^{*} \mathrm{CO}_{\mathrm{ONS}}$, * [REDUCED-V] respectively besides the faithfulness constraints which are ranked low in the language constraints' hierarchy. The Ekegusii's markedness constraints in this case dominate the faithfulness constraints which ensure correspondence between the underlying form and the surface forms.

On the other hand, weakening or voicing was observed in Ekegusii borrowing where the loanword had segments which are voiceless, but when mapping occurred, they became voiced as follows.

\begin{tabular}{|c|c|c|}
\hline $\begin{array}{l}\text { English Input } \\
/ \mathrm{t} \text { i:f } /\end{array}$ & $\begin{array}{l}\text { Ekegusii Output } \\
\text { [ecißu] }\end{array}$ & $\begin{array}{l}\text { English Gloss } \\
\text { 'chief' }\end{array}$ \\
\hline /refə'rendəm/ & [erißera $\left.{ }^{\text {ndamu}}\right]$ & 'referendum' \\
\hline /'trænsf3:/ & [eturansi $\beta a]$ & 'transfer' \\
\hline /'petrol/ & 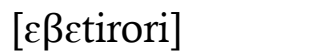 & 'petrol' \\
\hline /'hel1kpptə/ & [erikoßita] & 'helicopter' \\
\hline /'kıpəd/ & [ekaßati] & 'cupboard' \\
\hline /'kæptın/ & [ekaßuteni] & 'captain' \\
\hline /'prinsəpə1/ & [eßurin ${ }^{\mathrm{n}} \mathrm{si} \beta \mathrm{]}$ & 'principal' \\
\hline /'tæks1/ & [etayisi] & 'taxi' \\
\hline
\end{tabular}

Voicing/ weakening takes place where sounds $/ \mathrm{f} /, / \mathrm{p} /$ and $/ \mathrm{k} /$ become $/ \beta /, / \beta /$ and $/ \mathrm{\gamma} /$ respectively. Equally, in this case, the motivation is due to the absence of the 
voiceless sounds in Ekegusii apart from the mapping of $/ \mathrm{k} /$ to $/ \mathrm{\gamma} /$ whereby both sounds are in the Ekegusii language. Consonant voicing as a phonological process is not just unique to Ekegusii. It is also reported by Saleh and Jarrah (2013) in their study of English loanword phonology in Madin Hijazi Arabic (MHA).

Equally, OT can account for this voicing in that the markedness constraints *[CONT, LAB/DENT] and *[p] to punish the segments that have the voiceless labiodental fricative and the voiceless bilabial plosive can be invoked. Thus, it can be illustrated using inputs like / $\mathrm{gi}$ :f/ which is adapted as [ecißu] 'chief' and /'petrol/

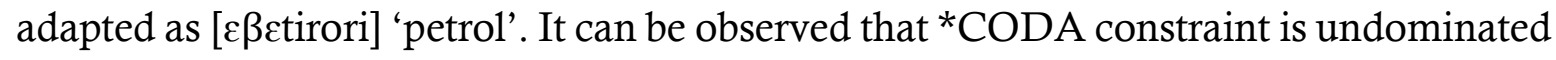
while ${ }^{*} \mathrm{CO}_{\mathrm{ONS}}$ is also invoked to punish complex cluster consonants. Further, the input has a schwa and a lateral; both of which are unattested in the language. Consequently, * [REDUCED-V] is proposed to punish segments with the reduced vowel and *[LAT] to punish segments which bear the laterals. Moreover, the outputs allow insertion of vowels and feature change. Therefore, the faithfulness constraints DEP-IO(V) and IDENT$\mathrm{IO}_{\mathrm{VOI} / \mathrm{LONG}}$ are invoked. The constraints are ranked as follows in Table $4 \mathrm{a}$ and $\mathrm{b}$ (3.4a) *CODA, *[CONT, LAB-DENT] >> DEP-IO(V), IDENT-IO VOI/LONG

$(3.4 \mathrm{~b}){ }^{*} \mathrm{CODA},{ }^{*}[\mathrm{p}],{ }^{*} \mathrm{CO}_{\mathrm{ONS}}$ *[REDUCED-V], *[LAT] >> DEP-IO-V, IDENT-IO

Table 4a. Mapping of / tfi:f/

\begin{tabular}{|c|c|c|c|c|}
\hline \multicolumn{3}{|c|}{ Table 4a. Mapping of / $\mathrm{gi}: \mathrm{f} /$} & \multicolumn{2}{|c|}{ [ecißu] 'chief' } \\
\hline$/ \mathrm{ti}: \mathrm{f} /$ & ${ }^{*} \mathrm{CODA}$ & $\begin{array}{l}* \text { [CONT, LAB- } \\
\text { DENT }]\end{array}$ & $\overrightarrow{\mathrm{DEP}-\mathrm{IO}}(\mathrm{V})$ & $\begin{array}{l}\text { IDENT- } \\
\text { IO }_{\text {VOI/LONG }}\end{array}$ \\
\hline a. $[$ e.ci. $\beta u]$ & & & * & * \\
\hline b. [fi:f] & *! & * & & \\
\hline c. [e. ci.fu] & & *! & * & \\
\hline d. [etf. $\beta u]$ & $* !$ & & * & * \\
\hline
\end{tabular}

From Table $4 \mathrm{a}$, candidate $(\mathrm{b})$ is the most disharmonic. It violates the high ranked markedness constraints *CODA and *[CONT, LAB-DENT]. Hence, it is eliminated. On the other hand, candidate (a) is the optimal. It satisfies the high ranked markedness constraints; *CODA and *[CONT, LAB-DENT] but violates the low ranked faithfulness constraints DEP-IO(V) which prohibits vowel insertion and IDENT-IO vol/LONG $_{\text {which }}$ disallows feature change. Thus, it minimally survives. As for candidates (c) and (d), they each violate the high ranked *[CONT-LAB-DENT] and *CODA respectively, thus they are eliminated.

\begin{tabular}{|c|c|c|c|c|c|c|c|}
\hline /'petral/ & *CODA & $*[\mathrm{p}]$ & ${ }^{*} \mathrm{CO}_{\mathrm{ONS}}$ & $\begin{array}{l}{ }^{*}[\mathrm{REDU} \\
\mathrm{CED}-\mathrm{V}]\end{array}$ & $*[\mathrm{LAT}]$ & $\begin{array}{l}\text { DEP- } \\
\mathrm{IO}(\mathrm{V})\end{array}$ & $\begin{array}{l}\text { IDENT- } \\
\mathrm{IO}_{\mathrm{VOI} / \mathrm{LAT}}\end{array}$ \\
\hline a. $[\varepsilon . \beta \varepsilon . t i . r o . r i]$ & & & & & & $* *$ & * \\
\hline b. [pe.trəl] & *! & * & * & * & * & & \\
\hline c. $[\varepsilon . \beta \varepsilon$. tro.li] & & & *! & & * & * & $* *$ \\
\hline d. [c.pe.ti.ro.ri] & & $* !$ & & & & ** & \\
\hline
\end{tabular}


Candidate (b) is the most disharmonic. It violates all the high ranked markedness constraints *CODA, *[P], ${ }^{*} \mathrm{CO}_{\mathrm{ONS}}$, [REDUCED-V] and *[LAT]; therefore, it does not survive. Conversely, candidate (a) is the optimal. Though it violates the low ranked faithfulness constraints IDENT-IO $\mathrm{VOI} / \mathrm{LAT}_{\mathrm{T}}$ and DEP-IO(V), it satisfies the high ranked markedness constraints; ${ }^{*} \mathrm{CODA},{ }^{*}[\mathrm{P}],{ }^{*} \mathrm{CO}_{\mathrm{ONSET}},{ }^{*}[\mathrm{REDUCED}-\mathrm{V}]$ and ${ }^{*}[\mathrm{LAT}]$. Candidate (c) allows a complex onset and the occurrence of a lateral sound that is not in the Ekegusii inventory besides violating the low ranked faithfulness constraints, thus, it does not survive. Lastly, candidate (d) is less harmonic compared to the winner. Whereas it violates just one markedness constraint * $[p]$ which Ekegusii language attaches importance to, and one faithfulness constraint by allowing vowel insertion, on this account it is eliminated. In this instance, the markedness constraints dominate the faithfulness constraints.

\section{Re-syllabification}

Syllabification results in a difference in the number of syllables in the input verses the output form. A period indicates a syllable boundary.

\begin{tabular}{|c|c|c|}
\hline $\begin{array}{l}\text { English Input } \\
/ \text { pin/ }\end{array}$ & $\begin{array}{l}\text { Ekegusii Output } \\
\text { [e.ßi.ni] }\end{array}$ & $\begin{array}{l}\text { English Gloss } \\
\text { 'pin' }\end{array}$ \\
\hline /boks/ & [e.ßo.yi.si] & 'box' \\
\hline /breik/ & [e.ßu.re.ki] & 'brake' \\
\hline /bærk/ & [e. $\beta$ e. $\mathrm{gg}$ i] & 'bank' \\
\hline /tæhk/ & [e.ta. $\left.{ }^{\mathrm{y}} \mathrm{g} \mathrm{i}\right]$ & 'tank' \\
\hline /vest/ & [e.ße.si.ti] & 'vest' \\
\hline /'kv. fən/ & [e.ko.so.ni] & 'cushion' \\
\hline /ke1k/ & [e.ke.ki] & 'cake' \\
\hline /ti:m/ & [e.ti.mu] & 'team' \\
\hline /'træns.f3:/ & [e.tu.ra. ${ }^{\mathrm{n}}$ si.ßa] & 'transfer' \\
\hline /'Ө3:məs/ & [e.ta.mo.si] & 'thermos' \\
\hline
\end{tabular}

In the data provided on loan adaptation in Ekegusii, English monosyllabic loans are replaced by disyllables and vowels inserted between or at the end of word which leads to an increase in the number of syllables in the output. Re-syllabification in adaptation of loanwords was also attested by Saleh and Jarrah (2013) in English loanword phonology in Madin Hijazi Arabic (MHA).

From the re-syllabification in Ekegusii, a number of constraints are imposed on the loanwords. First, ${ }^{*}$ CODA constraint, whereby Ekegusii forbids the presence of consonants in the coda. Consequently, loans that are monosyllabic and have codas are repaired via vowel insertion leading to an addition of syllables. Secondly, Ekegusii forbids onset cluster consonants except [CG] hence, a ${ }^{*} \mathrm{CO},{ }^{*} \mathrm{CN}$ and ${ }^{*} \mathrm{CL}$ constraints are applied accordingly to evaluate inputs. Where there is violation there is simplification via vowel insertion leading to re-syllabification. Hence, in an input like /vest/ 'vest' adapted as [e.ße.si.ti]; another markedness constraints that applies is *[CONT, LAB-DENT] which prohibits the occurrence of the voiced labial dental fricative. Further, in an attempt to make the loans fit in the Ekegusii phonology, the 
input violates the faithfulness conditions like DEP-IO(V) which forbids insertion of

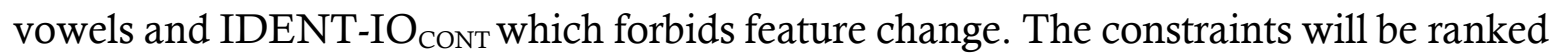
as follows: ${ }^{*} \mathrm{CODA},{ }^{*} \mathrm{CO}, *[\mathrm{CONT}-\mathrm{LAB}-\mathrm{DENT}]>>$ DEP-IO(V), IDENT-IO CONT. This is presented in Table (3.5).

\begin{tabular}{|c|c|c|c|c|c|}
\hline /vest/ & ${ }^{*} \mathrm{CODA}$ & ${ }^{*} \mathrm{CO}$ & $\begin{array}{l}*[\mathrm{CONT}, \\
\text { LAB-DENT] }\end{array}$ & $\begin{array}{l}\text { DEP- } \\
\text { IO(V) }\end{array}$ & IDENT-IO ${ }_{\text {CONT }}$ \\
\hline a. [vest] & *! & * & * & & \\
\hline b. [e.ße.sti] & & $* !$ & & * & * \\
\hline c. $[$ e.ße.si.ti] & & & & $* *$ & * \\
\hline $\mathrm{d}$ [e.ve.si.ti] & & & $* !$ & ** & \\
\hline
\end{tabular}

Table 5 shows that candidate (a) is the most disharmonic. It violates all the high ranked constraints; *CODA, *CO and *[CONT, LAB-DENT], thus, it is eliminated. Candidates (b) and (d) are isoharmonic. Each of them violates one of the high ranked otherwise markedness constraints ${ }^{*} \mathrm{CO}$ that forbids complex clusters and *[CONT, LAB-DENT] which disallows the occurrence of the labia dental fricative respectively as well as the low ranked faithfulness constraints hence, they too are eliminated. However, (c) minimally violates the low ranked faithfulness conditions in the Ekegusii thus, it optimally wins.

\section{Substitution}

Substitution is a phonological process that systematically changes a particular type of speech sound and replaces it with another (Sarkar, 2012). Data on loanwords indicated that substitution was very rampant in Ekegusii. Different English vocalic and consonants were mapped to Ekegusii as follows. The long /i:/ was realized as /1/, /æ/ as $/ \mathrm{e} /, / \mathrm{a} /$ or $/ \varepsilon /, / 3: /$ was realized as $/ \mathrm{a} /, / \mathrm{p} /$ as $/ \mathrm{o} /$ and one instance where it changed to $/ \mathrm{e} /$ and $/ \mathrm{v} /, / \mathrm{J} / /, / \Lambda /$ as $/ \mathrm{u} /$. The consonant sounds also were substituted as follows. $/ \mathrm{b} /, / \mathrm{p} /, / \mathrm{v} /, / \mathrm{f} /$ were adapted to $/ \beta /, / \mathrm{g} /$ was realized as $/ \mathrm{\gamma} /, / \mathrm{k} /, / \mathrm{g} \mathrm{g} /$ in different environments, $/ \mathrm{d} /, / \theta /$ changed to $/ \mathrm{t} /$ while $/ \mathrm{z} /, / \mathrm{J} / / \mathrm{z} /$ were adapted as $/ \mathrm{s}$ and $/ 1 /$ as $/ \mathrm{r} /$. As for manner-contour consonants 'mp' was realized as $/{ }^{\mathrm{m}} \mathrm{b} /$ in Ekegusii, while the English / $\mathrm{nk} /$ was replaced by $/{ }^{\mathrm{n}} \mathrm{g} /$ in Ekegusii. In all the instances of substitution, the phonological constraints of the Ekegusii language determined it. Cross-linguistically, substitution was also reported by Iribemwangi and Karuru (2012) on Gĩ-Gĩchũgũ which is a Bantu language. Similarly, Sarkar (2012) indicates substitution in Bangla borrowing.

OT's constraints can be used to account for vowel and consonant substitution. For vowels, consider an input like /' $\theta$ 3:məs/ adapted as [etamosi] 'thermos'. Specifically, the long mid open central unrounded vowel / $3: /$ is adapted as the open front unrounded vowel $/ \mathrm{a} /$. This two share the features [-back], [-round]. Equally, the schwa is not 
attested in the Ekegusii language; therefore, the markedness constraint *[REDUCED$\mathrm{V}]$ and IDENT-IO $\mathrm{IONG}_{\text {which }}$ is a faithfulness constraint that forbids feature change are proposed so as to punish any outputs that are illicit. Moreover, the *CODA constraint is undominated in the language thus, it is relevant. Further, it can be observed that Ekegusii repairs the voiceless dental fricative $/ \theta /$ to the voiceless alveolar stop $/ \mathrm{t} /$. The markedness constraint *[CONT, DENT] can account for this adaptation. In addition, the faithfulness constraints DEP-IO(V) can be proposed to account for the epenthesis in

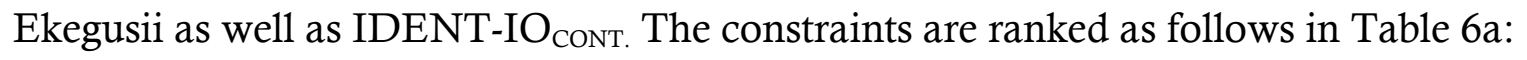

${ }^{*}$ CODA,$*$ [REDUCED-V], *[CONT-DENT] >> DEP-IO(V), IDENT-IO LONG/CONT

\begin{tabular}{|c|c|c|c|c|c|}
\hline \multicolumn{4}{|c|}{ Table 6a. Mapping of /' $\theta 3:$ məs/ } & imosi] & 'thermos' \\
\hline /'Ө3:məs/ & ${ }^{*} \mathrm{CODA}$ & $\begin{array}{l}* \text { [REDUCED- } \\
\mathrm{V}]\end{array}$ & $\begin{array}{l}{ }^{*}[\mathrm{CONT}, \\
\mathrm{DENT}]\end{array}$ & $\begin{array}{l}\text { DEP- } \\
\mathrm{IO}(\mathrm{V})\end{array}$ & $\begin{array}{l}\text { IDENT- } \\
\mathrm{IO}_{\text {LONG/CONT }}\end{array}$ \\
\hline a. $[$ e.ta.mo.si] & & & & * & $* *$ \\
\hline b. $[\theta 3: \mathrm{m} ә \mathrm{~s}]$ & $* !$ & * & * & & \\
\hline c. [e.ta.mə.si] & & *! & & * & $* *$ \\
\hline d. [e.ta.mos] & $* !$ & & & & $* *$ \\
\hline
\end{tabular}

According to Table 6a, candidates (b) is the most disharmonic. It not only violates the coda condition but also allows for the occurrence of a schwa and the dental fricative violating the high ranked markedness constraint *CODA, *[REDUCED-V] and *[CONT, DENT] which Ekegusii ranks highly. As for candidates (c) and (d), they violate the high ranked markedness constraints *[REDUCED-V] and *CODA both of which are ranked very highly in the Ekegusii besides the low ranked DEP-IO(V) and

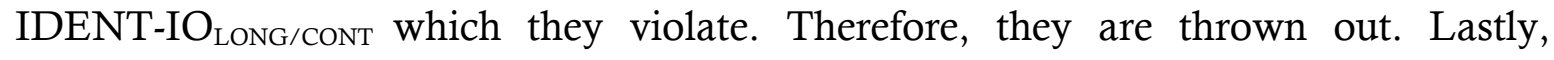
candidate (a) is the most harmonic, although it allows insertion of vowels, violating the

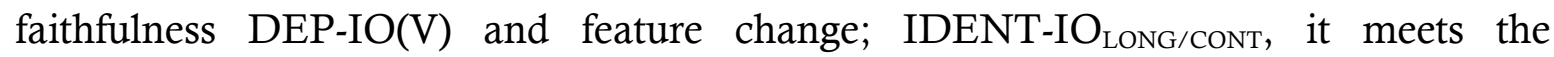
requirements of the high ranked undominated markedness constraints. Markedness constraints that demand structural markedness between the input and output dominate the faithfulness constraints that demand similarity between input and output.

On consonant substitution, we can consider the input /' $\mathrm{f} 11 \mathrm{l} \mathrm{y} /$ adapted as [esiring i] 'shilling'. In this adaptation, the voiceless alveolar fricative /s/ substitutes the voiceless post alveolar fricative $/ \mathrm{J} /$. Similarly, the trill $/ \mathrm{r} /$ is adapted in place of $/ 1 /$. OT's markedness and faithfulness constraints can be invoked to account for this phenomenon. First, the ${ }^{*}$ CODA constraint that is undominated in the Ekegusii language is proposed. Secondly, the two sounds are coronals. Hence, the markedness constraint *[j] which is undominated just like *CODA is relevant. Thirdly, is the markedness constraint *[LAT] that prohibits the occurrence of a lateral sound in Ekegusii. In addition, there is no correspondence between the input and the output. In fact, there is vowel insertion making the output violate DEP-IO(V) as well as feature change DEP-IO LAT/NAS/DISTR. $_{\text {. }}$ 
The constraints will be ranked as follows in Table (3.6b) *CODA, * []], *[LAT] >> DEP$\mathrm{IO}(\mathrm{V})$, IDENT-IO LAT/NAS/DISTR

Table 6b. Mapping of /'filıy/ $\longrightarrow$ [esiringi] 'shilling'

\begin{tabular}{|c|c|c|c|c|c|}
\hline /'silı/ / & *CODA & $*[j]$ & $*[\mathrm{LAT}]$ & $\begin{array}{l}\text { DEP- } \\
\text { IO(V) }\end{array}$ & IDENT-IO LAT/NAS/DISTR \\
\hline a. [J1.lin] & *! & * & * & & \\
\hline b. [e.fi.ri. " g i] & & *! & & * & ** \\
\hline c. $\left[\right.$ e.si.ri. ${ }^{\prime} g$ i] & & & & * & $* * *$ \\
\hline d. [e.si.li.”g i] & & & *! & * & $* *$ \\
\hline
\end{tabular}

As shown in Table $6 \mathrm{~b}$, the markedness constraints dominate the faithfulness constraints. Thus, Ekegusii ranks the markedness language constraints of *CODA, *[j]

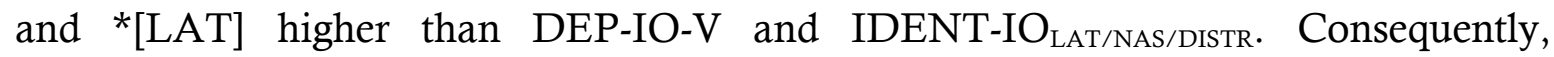
candidate (c) is the most harmonic since it does not violate any of these constraints that Ekegusii language ranks highly. As for candidate (b) and (d), they are isoharmonic. They each violate one of the high ranked markedness constraint, * []] and *[LAT] besides the faithfulness constraints, as a result they are eliminated. Candidate (a) is the most disharmonic, it violates all the markedness constraints by allowing a coda, a lateral and voiceless post alveolar fricative sound in the output, all which are not attested in the language. Hence, it is eliminated.

\section{Monophthongization}

Monophthongs are simple vocalic sounds that have a steady state articulation; that is, tongue, lips and jaw are meant to achieve -however brief- a stable configuration called a target configuration (Clark et al., 2007). Monophthongization occurs when diphthongs are reduced to simple pure vowels.

\begin{tabular}{|c|c|c|}
\hline $\begin{array}{l}\text { English Input } \\
\text { /ke1k/ }\end{array}$ & $\begin{array}{l}\text { Ekegusii Output } \\
\text { [ekeki] }\end{array}$ & $\begin{array}{l}\text { English Gloss } \\
\text { 'cake' }\end{array}$ \\
\hline /bre1k/ & [eßureki] & 'brake' \\
\hline /'be1kər1/ & 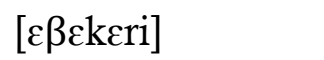 & 'bakery' \\
\hline /'e1kə/ & 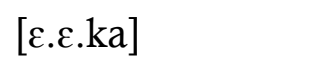 & 'acre' \\
\hline /'rəolə]/ & [عrore] & 'roller' \\
\hline /ri'məむt/ & [erimoti] & 'remote' \\
\hline /'bə1rəu/ & [eßiro] & 'biro' \\
\hline /'la1səns/ & [eresesi] & 'license' \\
\hline
\end{tabular}

In all the instances of monophthongization, the motivation is absence of the diphthong in the Ekegusii language. Subsequently, the pure vowels that replace the diphthongs are similar to those on the loanword. A case in point is /ei/ changes to either /e/ or / $\varepsilon /, / \partial \mho /$ is adapted as /o/ while /ə1/ and /a1/ are substituted by /1/ and /e/ respectively. Monophthongization was similarly reported by Faezeh and Zafaranlu 
(2013) whereby there is reduction of diphthongs in German loanwords so as to fit the Persian phonology.

OT can account for this monophthongization in Ekegusii. Let us illustrate using /əo/ which is simply reduced to /o/ with which it shares features [+round, +back]. OT's universal markedness constraint *CODA and the language's well-formedness constraints *DIPH, accounts for the adaptation of /o/ in Ekegusii. Further, from the data it can be inferred that different Ekegusii outputs allow for the epenthesis of vowels and feature change. Thus, we can add the faithfulness constraints of DEP-IO $(\mathrm{V})$ and IDENT-IO $_{\text {DIPH }}$ to account for these changes in case of/ ri'məot/ being adapted as [erimoti] 'remote'. The constraints are ranked as follows:

${ }^{*} \mathrm{CODA},{ }^{*} \mathrm{DIPH}>>\mathrm{MAX}-\mathrm{IO}_{\mathrm{SEG}}>>$ DEP-IO(V), IDENT-IO $\mathrm{IIPH}$

Table 7. Mapping of $/ \mathrm{ri}$ 'movt/ $\longrightarrow$ [erimoti] 'remote'

\begin{tabular}{lllll}
\hline /ri'məut/ & $*$ CODA & ${ }^{*}$ DIP & MAX- & DEP-IO(V) \\
& $\mathrm{H}$ & IO $_{\text {SEG }}$ & IDENT-IO $_{\text {DIPH }}$
\end{tabular}

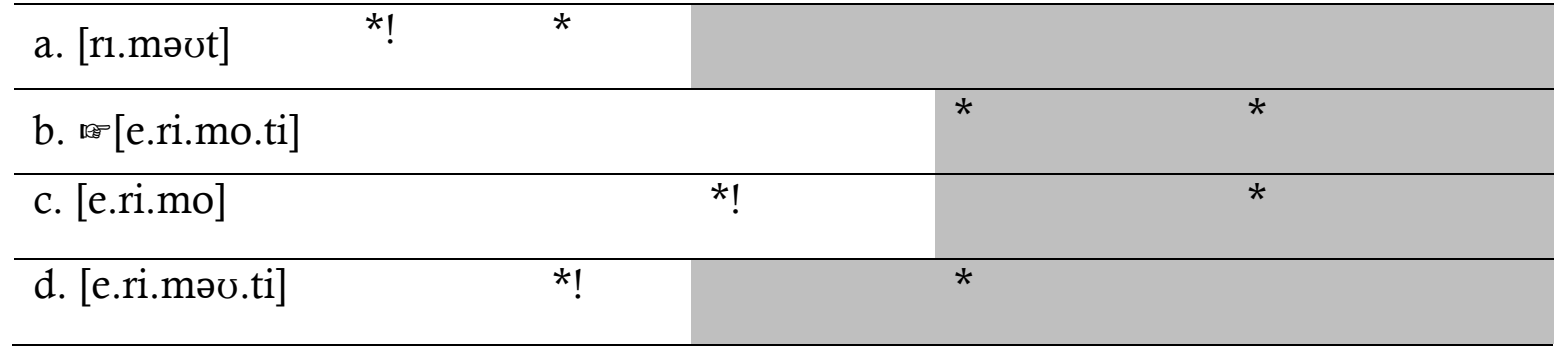

Table (3.7) indicates that candidate (a) is the most disharmonic. It violates both of the high ranked ${ }^{*} \mathrm{CODA}$ constraint and the ${ }^{*} \mathrm{DIPH}$ constraint that prohibits the occurrence of coda consonants and diphthongs respectively. On the other hand, (b) is the most harmonic despite the fact that it violates DEP-IO(V) by allowing insertion of vowels and changes the diphthong to a simple vowel. As for candidate (d) it violates the high ranked markedness constraint * DIPH and the low faithfulness constraints, hence it is eliminated. Candidate (c) does not fare well either, though it violates a faithfulness constraint; MAX-IO $\mathrm{SEG}_{\mathrm{SE}}$, this constraint is ranked above other faithfulness constraints although it is dominated by the markedness constraints. Hence, candidate (c) is eliminated.

\section{Lenition}

This is a phonological process that alters sound segments by weakening them. For instance, consonants can be changed from voiceless to voiced, plosives to fricatives sounds among others. For vowels, both back and front vowels are stronger than central vowels. Thus, if they are altered to the latter they are weakened. The following are some of the cases of lenition identified in the data collected.

$\begin{array}{lll}\text { English Input } & \text { Ekegusii Output } & \begin{array}{l}\text { English Gloss } \\ / \text { 'bændidz/ }\end{array} \\ {\left[\mathrm{e} \beta \mathrm{a}^{\mathrm{n}} \mathrm{deci}\right]} & \text { 'bandage' }\end{array}$




$\begin{array}{lll}\text { /'bætar1/ } & {[\varepsilon \beta \varepsilon t 1 r 1]} & \text { 'battery' } \\ \text { /bre1k/ } & {[\mathrm{e} \beta \text { ureki] }} & \text { 'brake' } \\ \text { /'be1kər1/ } & {[\varepsilon \beta \varepsilon k e r i]} & \text { 'bakery' } \\ \text { /bæyk/ } & {\left[\mathrm{e} \beta \mathrm{e}^{\mathrm{n}} \mathrm{g} \text { i] }\right.} & \text { 'bank' } \\ / \text { 'bæptım/ } & {[\mathrm{e} \beta \text { atiso] }} & \text { 'baptism' }\end{array}$

The voiced bilabial plosive /b/ is weakened to the voiced bilabial fricative $/ \beta$ / which is the closest in the Ekegusii inventory. Similarly, the voiced palatal affricate /dz/ is adapted as the voiceless palatal plosive /c/ while the central vowel /ə/ is adapted as the mid low open vowel /e/. In the adaptation of /'bændids/ as [e $\beta \mathrm{a}^{\mathrm{n}} \mathrm{deci}$ ], though the voice is maintained it is weakened in the mapping of bilabial plosive $/ \mathrm{b} /$ to the bilabial fricative $/ \beta /$ while the voice is lost in the adaptation of $/ \mathrm{dz} / \mathrm{as} / \mathrm{c} /$. This adaptation can be accounted for using OT. Ekegusii language imposes a markedness constraint on the incoming loan that they should not violate *OBSVOI besides the universal constraint of ${ }^{*}$ CODA which is ranked high in the hierarchy. Besides, the voiced bilabial plosive /b/ is not attested in the Ekegusii language. Hence, the markedness constraint $*[b]$ is relevant. All these proposed are markedness constraints which have to interact with faithfulness constraints. Thus, from the input output mapping there is feature change in terms of voice and a stop changing to a continuant; IDENT VOI/CONT $_{\text {and DEP-IO(V) }}$ which is anti-epenthesis are invoked. The constraints will be ranked as:

*CODA, *[b] >> *OBSVOI >> IDENT VOI/CONT, $_{\text {DEP-IO(V) }}$

\begin{tabular}{|c|c|c|c|c|c|}
\hline /'bændidz/ & ${ }^{*} \mathrm{CODA}$ & $*[\mathrm{~b}]$ & *OBSVOI & $\begin{array}{l}\text { IDENT- } \\
\mathrm{IO}_{\mathrm{VOI} / \mathrm{CONT}}\end{array}$ & DEP-IO(V) \\
\hline a. [bæ.ndidz] & *! & * & * & & \\
\hline b. [e.ba. ${ }^{n}$ di.dz1] & & *! & * & & * \\
\hline c. $\left[\right.$ e. $\beta a .{ }^{n}$ de.ci $]$ & & & & $* *$ & * \\
\hline d. [e.ßa. ${ }^{n}$ dedz] & $* !$ & & * & * & \\
\hline
\end{tabular}

Table 8 shows that (c) is the most harmonic. Although it violates the low ranked

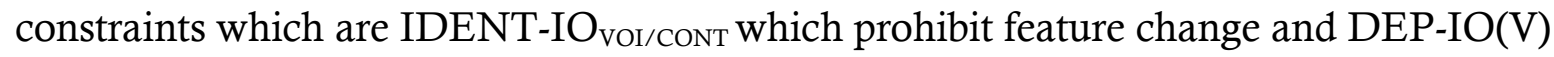
which forbids insertion, it satisfies the high ranked markedness constraints which are ${ }^{*}$ CODA, * $[\mathrm{b}]$ and *OBSVOI. On the other hand, candidate $(b)$ and $(d)$ are isoharmonic. They each violate two of the high ranked markedness constraints; *[b], *OBSVOI and ${ }^{*}$ CODA, *OBSVOI respectively, hence they are eliminated. Lastly, candidate (a) is the most disharmonic. Though it does not violate any of the faithfulness constraints which are ranked low in the Ekegusii language, it violates all the high ranked markedness constraints which are ${ }^{*}$ CODA, ${ }^{*}[b]$ and ${ }^{*}$ OBSVOI, thus it is eliminated.

\section{CONCLUSION}

The article examined the phonological processes in Ekegusii borrowing from English. It can be concluded that various phonological processes were realised because the languages differ in their phonologies. The phonological processes attested included: 
epenthesis, deletion, weakening/voicing, strengthening/devoicing, re-syllabification, substitution, lenition, and monophthongization. Firstly, on epenthesis, it was motivated by consonant cluster simplification either at syllable onset or coda, and there was no predictable pattern governing the kind of vowel to be inserted. Secondly, is deletion which took the form of aphaeresis and syncope. Thirdly is devoicing or strengthening, which was observed when voiced obstruents were devoiced. This strengthening was motivated by the absence of the voiced obstruents in the Ekegusii inventory in addition to the fact that voiceless sounds are unmarked and cross-linguistically preferred over the voiced sounds. Re-syllabification was another phonological process whereby English monosyllabic loans were replaced by disyllables and vowels inserted between clusters or at the coda because of Ekegusii's open syllabicity. Substitution also occurred in Ekegusii borrowing, mainly driven by the absence of a given sound in the Ekegusii inventory. Absence of diphthongs in the Ekegusii led to monophthongization, whereby the pure vowels replaced the English diphthongs in the loanwords. Lastly, lenition was observed whereby by the plosive sounds were realized as fricatives. Considering the reviewed literature and the findings discussed herein, it can be noted that borrowing across languages (related or unrelated) reports similar if not the same phonological processes only that the processes attested in one language are a subset of the universally exhibited processes.

\section{REFERENCES}

Bowern, C. (2008). Linguistic fieldwork: A practical course. Palgrave Macmillan.

Clark, J. (John E., Yallop, C., \& Fletcher, J. (2007). An introduction to phonetics and phonology.

Farazandeh-pour, F., Kord, A., \& Kambuziya, Z. (2013). German Loanwords Adaptation in Persian : Optimality Approach. 20.

Fossi, A., \& Ouafo Lambo, A. (2012). Cultural and Linguistic Hybridizations in Cameroon: English Loanwords in ngômbà. International Journal of Linguistics, 4(1), 267-286. https://doi.org/10.5296/ij1.v4i1.1148

Gussenhoven, C., \& Jacobs, H. (2005). Understanding phonology. Hodder Education.

Guthrie, M. (1971). Comparative Bantu: An Introduction to the Comparative Linguistics and Prehistory of the Bantu Languages, Volumes 1-4. Gregg.

Iribemwangi, P. I., \& Karũ rũ , D. W. (2012). Phonological Adaptation of Kiswahili Loanwords into Gĩ-Gĩchũgũ Dialect of Gĩkũyũ Language. 49-62. https://www.researchgate.net/publication/324603764_Phonological_Adaptation _of_Kiswahili_Loanwords_into_Gi-Gichugu_Dialect_of_Gikuyu_Language

Kager, R. (1999). Optimality Theory. Cambridge University Press.

Kioko, A. N., \& Muthwii, M. J. (2001). The demands of a changing society: English in 
education in kenya today. Language, Culture and Curriculum, 14(3), 201-213. https://doi.org/10.1080/07908310108666622

Mose, E. G. (2020). A morphophonological analysis of borrowed segments in Ekegusii language: An Optimality Perspective. Unpublished $\mathrm{PhD}$ thesis, Kenyatta University, Nairobi, Kenya.

Mwita, L. C. (2009). The Adaptation of Swahili Loanwords from Arabic: A ConstraintBased Analysis. Journal of Pan African Studies, 2(8), 46.

Nandelenga, H. S. (2013). Constraint Interaction in the Syllabic Phonology of Lubukusu: an Optimality Theory Account. Kenyatta University.

Ogechi, N. O., \& Kembo-Sure. (2006). Language planning for development in Africa. Moi University Press.

Prince, A., \& Smolensky, P. (1993). Optimality Theory: Constraint Interaction in Generative Grammar. Optimality Theory in Phonology: A Reader, 1-71. https://doi.org/10.1002/9780470756171.ch1

Sri Ayuni Restifiza, R. N. R. (2012). PHONOLOGICAL PROCESSES OF INDONESIAN BORROWING WORDS USED BY MINANGKABAUNESE IN BUKITTINGGI, WEST SUMATERA. English Language and Literature, 1(1). https://doi.org/10.24036/ELL.V1I1.1835

Tsvetkov, Y., \& Dyer, C. (2016). Cross-Lingual Bridges with Models of Lexical Borrowing. Journal of Artificial Intelligence Research, 55, 63-93. https://doi.org/10.1613/jair.4786

Prince, A., \& Smolensky, P. (1993). Optimality theory: Constraint interaction in generative grammar. New Brunswick, NJ: Rutgers University.

Prince, A., \& Smolensky, P. (2004). Optimality Theory: Constraint interaction in generative grammar. Maiden: Blackwell Publishing.

Sarkar, T. (2012). Loanword adaptation in Bangla: An optimality theoretic account. MA thesis, The English and Foreign Languages University. Hyderabad, India.

Saleh, A. J., \& Jarrah, R. S. (2013). English loanwords spoken by Madinah Arabic $\begin{array}{llll}\text { speakers. Arab World English Journal, } & \text { 4(2), }\end{array}$ https://awej.org/images/AllIssues/Specialissues/Translation2/5.pdf

National Council for Law Reporting (2010). The Constitution of Kenya, 2010. Published with the Authority of the Attorney General.

Zafaranlu, K. A., \& Hashemi, S. E. (2011). Russian loanwords adaptations in Persian; Optimal approach. Iranian Journal of Applied Linguistic Studies, 3(1), 1-17. https://files.eric.ed.gov/fulltext/ED525228.pdf 